\title{
PREVALENCE AND OUTCOME OF SURGERY FOR FEMALE INCONTINENCE*
}

\author{
ANANIAS C. DIOKNO, M.D. \\ MORTON B. BROWN, PH.D. \\ BRUCE M. BROCK, PH.D. \\ A. REGULA HERZOG, Ph.D. \\ DANIEL P. NORMOLLE, PH.D.
}

From the Department of Surgery-Urology, Medical School, University of Michigan, Ann Arbor, and the Department of Urology, William Beaumont Hospital, Royal Oak, Michigan

\begin{abstract}
A 4.7 percent surgery rate to correct urine loss conditions was found by a large scale survey of sixty-year and older non-institutionalized women in a Michigan county. The initial postoperative results reported by the respondents were 74 percent complete continence and 23 percent partial relief. The long-term self-reported outcomes (two years or more post-surgery) were an absolute continence rate of 39 percent and 17 percent with mild incontinence (the median time since surgery was 12 years), whereas the short term (4-23 months, mean 7.1 months) absolute continence rate was 71 percent. The characteristics of the incontinence respondent who had previous surgery showed 70 percent having mixed stress-urge type of incontinence and 66 percent losing urine almost weekly or daily. Bladder emptying symptoms were reported by 30.4 percent of the continent previously-operated respondents compared with 13.0 percent of the incontinent previously-operated respondents. All continent respondents and 84 percent of the incontinent respondents believed that physicians can help people with a urine loss condition.
\end{abstract}

Bladder suspension procedure is an accepted form of surgical treatment for women with primary (genuine) stress urinary incontinence. ${ }^{1,2}$ The utilization rate and collective outcomes of anti-incontinence surgery in a communitybased sample have not been reported previously. However, numerous reports on the outcome of the different bladder suspension procedures have been reported by surgeons from different clinical settings. ${ }^{3-5}$

We have recently completed a large scale survey using a probability sample of elderly men and women in Washtenaw County, Michigan to determine the prevalence of urinary incon-

\footnotetext{
*Supported by a grant award from the National Institutes on Aging, grant number 1 PO1, AGO 3742 .
}

tinence in this population. ${ }^{6}$ As part of our study, we inquired into previous surgery to correct past urine loss conditions among women to determine the prevalence of such treatment, and the short- and long-term outcomes of such operations.

\section{Material and Methods}

\section{Survey questions}

To identify women who had previous incontinence surgery the question used was, "Have you ever had any surgery to correct a past urine loss condition?" If the answer was yes, the following questions were asked: "How many such operations have you had?", "How long ago did you have that (last) operation?", "What was the 
TABLE I. Categorization of severity of incontinence

\begin{tabular}{|c|c|c|c|c|}
\hline \multirow{2}{*}{$\begin{array}{c}\text { Quantity } \\
\text { (in Increasing Order) }\end{array}$} & \multicolumn{4}{|c|}{-Frequency (Days/Year) } \\
\hline & $1-9$ & $10-49$ & $50-299$ & $300+$ \\
\hline$<1 / 2 t$ & Mild & Mild & Mild & Seve \\
\hline$<1$ tablesp & Mild & Moder & Mod & Severe \\
\hline$<1 / 4$ cup & Mild & Modera & Moderate & Severe \\
\hline $1 / 4$ cup or more & Mild & Moderate & Severe & Severe \\
\hline
\end{tabular}

operation called?", and "Initially, did the surgery help you to regain complete or partial control over your bladder, or didn't it help at all?"

To probe the long-term outcome of the antiincontinence surgery, response to the key question on incontinence was determined. The question was, "In the past twelve months, about on how many days have you lost any urine, even a small amount beyond your control?" Any respondent who reported losing urine of any volume with a minimum frequency of six days within the last twelve months was considered to be incontinent. When the urine loss was less than six days, the respondent was probed further to determine if it fit any of the known mechanisms of urine loss, such as stress and/or urge loss. If the criteria fit, the respondent was considered to be incontinent of urine. When the answer was negative, the respondent was asked whether he or she was certain that there had not been any days when any amount of urine was lost at all.

\section{Determination of severity}

The incontinent respondents were further questioned regarding the severity of incontinence based on the frequency and quantity of urine loss. The clinical typology of incontinence based on the four conventional types (stress, urge, mixed, and others) was also determined. The questions used for the severity issue and the definitions used for the conventional types of incontinence have been presented previously. ${ }^{6}$

The measure of severity was constructed based on the frequency and quantity of incontinent episodes, as shown in Table $1 .^{7}$

\section{Voiding Symptoms}

The voiding symptoms of all respondents who had anti-incontinence surgery were also obtained. The questions for the frequency of voiding were as follows: "In general, over a twenty-four-hour period, about how many times do you go to the toilet and urinate?" and "Generally how many times do you usually urinate after you have gone to sleep at night?"
To determine the symptoms of irritation and a recent history of urinary infection, the following questions were asked: "Have you had any problems with pain, burning or stinging when you urinate?" and "In the past twelve months, that is in the past year, have you had any urinary tract infections?"

To determine bladder emptying symptoms, the following questions were asked: "In the past twelve months, have you had any trouble starting your urine flow when you wanted to?", "Have you had to use a catheter or urine tube to empty your bladder?", and "Have you had to push or strain to urinate rather than letting your bladder go on its own?"

\section{Statistical Analysis}

The data from the survey represent a one seventh equal probability sample of the elderly population in Washtenaw County, Michigan; the frequencies of five-year age groupings by gender agree closely with published census data. Therefore, no weighting of the data was performed.

Percents are reported excluding missing data from nonresponses or "don't know" (NR/DK). Two-way frequency tables were formed and chi-square statistics $\left(\chi^{2}\right)$ were computed.

\section{Results}

\section{Surgery utilization rate and incontinence rates}

Fifty-four women of 1,148 female respondents $(4.7 \%)$ reported that they had surgery to correct a past urine loss condition (antiincontinence surgery). Initial complete relief of incontinence due to the surgery was reported by 39 respondents $(73.6 \%$ of 53 respondents, one $\mathrm{NR} / \mathrm{DK}$ ), partial relief was reported by 12 $(22.6 \%)$, and no relief by two $(3.8 \%)$. The current long-term continence status of the 46 respondents that are two or more years post surgery is 39.1 percent absolute continence, 17.4 percent with mild incontinence, 15.2 percent with moderate incontinence, 26.1 percent with 
TABLE II. Frequency of women classified by length of time from surgery and incontinence status

\begin{tabular}{|c|c|c|c|c|}
\hline \multirow{2}{*}{$\begin{array}{c}\text { Years } \\
\text { From } \\
\text { Surgery }\end{array}$} & \multicolumn{2}{|c|}{$\begin{array}{c}\text { Only One } \\
\text { Surgery } \\
\text { Continent }\end{array}$} & \multicolumn{2}{|c|}{$\begin{array}{l}\text { More Than } \\
\text { One Surgery } \\
\text { Continent }\end{array}$} \\
\hline & Yes & No & Yes & No \\
\hline$<2$ & 3 & 1 & 2 & 1 \\
\hline $2-5$ & 3 & 3 & 3 & 1 \\
\hline $6-10$ & 0 & 7 & 2 & 0 \\
\hline $11-15$ & 6 & 11 & 1 & 0 \\
\hline $16+$ & 2 & 5 & 1 & 1 \\
\hline $\mathrm{NR} / \mathrm{DK}$ & 0 & 1 & & \\
\hline Totals & 14 & 28 & 9 & 3 \\
\hline & 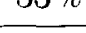 & & & \\
\hline
\end{tabular}

severe incontinence, and 2.2 percent unclassified (did not respond to the questions on severity). The short-term outcome (4 months to 23 months, mean 7.1 months) for absolute continence is 71.4 percent.

Thirty-seven of the 46 women $(80.4 \%)$ two or more years postsurgery had one surgery, six had two, and three had three to six operations. Among the 37 with only one surgery, 29.7 percent claimed to be currently continent; among the 9 with more than one operation, the selfreported continence rate was 77.8 percent; the difference between these proportions is significant $\left(\chi^{2}=7.02, p<0.01\right)$.

The lengths of time since surgery by selfreported continence status are reported in Table II. The median time from surgery for women with one surgery is twelve years and for women with more than one surgery is four years. The median time from surgery of all the women is eleven years. The women with less than five years from surgery report a higher rate of absolute continence than those with more time. However, this would not explain the difference between the continence rates for women with one surgery and women with more than one in those who are more than five years postsurgery $\left(25 \%\right.$ and $80 \%$, respectively, $\chi^{2}=5.98, p<$ $0.02)$.

\section{Clinical types and frequency of current incontinence}

The characteristics of urine loss reported by 31 women who had previous anti-incontinence surgery were: 71 percent mixed, and 10 percent each in the stress, urge, and other groups.

The frequency of urine loss among 30 operated respondents (one did not respond) were: 33 percent losing urine 300-365 days per year, 30 percent with frequency of 50-299 days, 7 percent with frequency of 10-49 days, and 30 percent with frequency of 1-9 days. This distribution differed significantly from that for incontinents who were not operated (Table III). The number of days of urine loss for incontinents in the nonsurgical group was less than that in the surgical group.

\section{Voiding frequency}

The total voiding frequency per day was divided into normal (1-8 times a day) and high (9 times or more per day). High voiding frequencies were reported by 35 percent $(8)$ of the operated continent respondents and by 48 percent (15) of the operated incontinent respondents. The nightly frequency of voiding also did not differ between the two operated groups, 79 percent (15) in the continent group and 77 percent (20) in the incontinent operated group did not have any nocturia.

\section{Bladder symptoms}

The frequencies of bladder emptying difficulty and of irritation and/or infection are presented in Table IV. Of the 17 respondents in the surgical group who reported infection, all but 2 also reported irritation, and there were no subjects who reported irritation in the absence of infection. Similarly, all but 48 of the 143 respondents who reported infection in the nonsurgical group also reported irritation; again,

TABLE III. Frequency (percent) of women classified by number of days per year that incontinent episodes occurred and by anti-incontinence surgery

\begin{tabular}{lrrrrrr}
\hline & \multicolumn{7}{c}{ No. of Days per Year- } & & \\
\cline { 2 - 7 } Surgery & $1-9$ & $10-49$ & $50-299$ & $300-365$ & Total & NR/DK \\
\hline Yes $(\%)$ & $9(30)$ & $2(7)$ & $9(30)$ & $10(33)$ & 30 & 1 \\
No. $(\%)$ & $130(34)$ & $113(29)$ & $77(20)$ & $64(17)$ & 384 & 19 \\
\hline${ }^{*} \chi^{2}=10.96, p<0.01$. & & & & &
\end{tabular}


TABLE IV. Frequency (percent) of respondents classified by surgery, symptoms, and continence status*

\begin{tabular}{llrlll}
\hline $\begin{array}{l}\text { Continent } \\
\text { Status }\end{array}$ & \multicolumn{1}{c}{ Asx. } & Irrit./Inf. & Empty Sx. & Both & Total \\
\hline \multicolumn{2}{r}{ Respondents } & with previous anti-incontinence surgery & & \\
Continent & $12(52.2)$ & $4(17.4)$ & $3(13.0)$ & $4(17.4)$ & $23(100)$ \\
Incontinent & $20(64.5)$ & $7(22.6)$ & $2(6.5)$ & $2(6.5)$ & $31(100)$ \\
Total & $32(59.3)$ & $11(20.4)$ & $5(9.3)$ & $6(11.1)$ & $54(100)$
\end{tabular}

Respondents without previous anti-incontinence surgery

\begin{tabular}{lrrrrr} 
Continent & $574(82.5)$ & $79(11.4)$ & $29(4.2)$ & $14(2.0)$ & $696(100)$ \\
Incontinent $289(71.5)$ & $64(15.8)$ & $24(5.9)$ & $27(6.7)$ & $404(100)$ \\
Total & $863(78.5)$ & $143(13.0)$ & $53(4.8)$ & $41(3.7)$ & $1100(100)$ \\
\hline
\end{tabular}

${ }^{*}$ Figures in parentheses indicate percent.

KEY: Asx = asymptomatic; irrit./inf = irritation/infection; empty sx = emptying symptoms.

there were no cases of irritation without infection. Therefore, we have combined the two symptoms in Table IV.

Among respondents who underwent surgery, 59 percent did not report any of the three bladder symptoms: infection, irritation, or difficult bladder emptying. In contrast, 78.5 percent of the nonsurgical respondents reported that they are asymptomatic (Table IV). The two groups were then compared separately based on continence status. Among continent respondents, the proportion who are asymptomatic in the surgical group is significantly less than in the nonsurgical group $\left(52 \%\right.$ vs $82.5 \%, \chi^{2}=14.0$, $p<0.005$ ), but there is no significant difference in the proportion of asymptomatic respondents between the incontinent groups (65\% vs $71.5 \%$, respectively).

Examination of Table IV indicates that the decreased proportion of asymptomatic continent respondents among the surgical group is due to increased proportions of respondents with both symptoms of difficult bladder emptying and infection and/or irritation ("both symptoms" in Table IV) $\left(\chi^{2}=21.6, p<0.001\right)$. Because of the large increase in those with "both" symptoms, tests of the increase for each symptom separately are also significant. However, the test for an increase in only one symptom, or pure category, unaccompanied by the "both" symptom, is not significant for irritation/ infection and marginally significant for bladder emptying difficulty.

\section{Belief about physicians}

Eighty-four percent of the incontinent operated respondents and 100 percent of the continent operated respondents answered positively to the question whether "there is anything that doctors can do to help people who have a urine loss condition?" Sixty-eight percent of incontinent operated respondents and 83.3 percent of continent operated respondents answered in a positive manner to "how effective are doctors in helping people who have a urine loss condition?"

\section{Comment}

Surgery to correct urine loss is still the most widely accepted treatment for stress urinary incontinence. It has the potential of producing a permanent absolute cure to their incontinence. In this survey 39 percent of our respondents have achieved absolute continence for a median follow-up of twelve years. This long-term continence rate is lower than previously reported rates. ${ }^{8.9}$ One reason for the lower rate may be attributed to the fact that the continence rate is based on self-report of absolutely no urine loss for 365 days. If the respondents who have lost urine nine days or less in a year are added to the continent group, the long-term continence rate then would be 50 percent, which is similar to the cure rates of 57 to 61 percent reported by Spencer et al. ${ }^{10}$

The use of absolute continence rate also eliminated respondents who may have been cured of the stress incontinent symptoms, but continue to be incontinent because of a non-stress incontinent mechanism such as overflow or an overactive detrusor. If these latter respondents were added to the continent group, the continence rate would increase to 59 percent.

The overall lower long-term postoperative continence rate may also be attributed to the length of the follow-up period. The follow-up period in this series has a median of twelve years in contrast to a six to twenty-four months follow-up period in many individually reported series. Our survey shows that those with longer 
follow-ups have a lower incontinence rate which indicates that recurrence may be occurring beyond the usual six-month period that is considered an adequate follow-up for these procedures. The delayed recurrence of incontinence beyond the six-month follow-up was also observed by Spencer et al. ${ }^{10}$ in 66 percent of their patients who failed the bladder suspension operations.

Since the absolute continence rate following only one surgery after five years is only 25 percent when compared with those who had more than one surgery which is 80 percent, the discrepancy is unlikely to be a reflection of the length of follow-up. The discrepancy may be due to the difference regarding the indications and techniques used. The procedure done in most women who had only one surgery, or the first surgery performed when there were multiple surgeries, may have been an anterior colporrhaphy since the philosophy a decade or more ago was: "First do a vaginal operation for stress incontinence: if there is anatomical failure or recurrence of symptoms, then do an operative procedure by the abdominal route, that is, a retropubic operation." 11 It is now known that anterior colporrhaphy has a failure rate as high as 50 percent. ${ }^{11}$ Advances in recent years have allowed surgeons to distinguish the different mechanisms of stress loss and to apply a specific surgical technique that is appropriate for each patient. This may explain the improved continence rate attained by the recently-operated or the reoperated respondents. Unfortunately the questionnaire responses did not contain sufficient detail to analyze the approach and technique used on each respondent. However, in spite of these shortcomings, these results are important since it gives us some general insight as to how antiincontinence surgery, regardless of the surgeon and the technique, succeeds in a community population. These results confirm that anti-incontinence surgery can confer long-lasting continence for some incontinent women. Moreover, these results suggest that the definition of long-term outcome should be longer than six months, preferably a minimum of two years, and that the efficacy of a surgical technique should be based on a minimum of two years of follow-up.

The increased severity of incontinence among the operated respondents is probably a reflection of the more severe type of incontinence subjected to the operation. When the operation fails, the incontinence presumably reverts back to the previous level of severity.

An important observation of this study is that urologic symptoms are reported more by the operated respondents than the non-operated respondents. Furthermore, there are more symptoms of both bladder emptying and irritation/ infection among the continent-operated respondents than the other three categories. It is possible that these symptoms were pre-existent and that the operation did not influence the postoperative outcome. However, the fact that there is a significantly higher rate of both difficult bladder emptying and irritation/infection symptoms among the continent surgical group than among the continent nonsurgical group, but not between the parallel incontinent groups, suggests that the symptoms may have been induced by the operation.

The postoperative voiding symptoms were also acknowledged by previous investigators. ${ }^{10,12}$ However, no comparison was made of the incidence of the voiding symptoms between the successful operated and failed subjects. Moreover, since the reported series are mainly clinical series, there are no comparisons between operated and non-operated subjects. It is presently unknown whether the surgical procedure precipitates the appearance of the bladder symptoms in subjects with preoperative subclinical detrusor hypotonia, outlet obstruction, or bladder overactivity.

The responses to the belief questions regarding physicians seem to confirm the positive experience that previously operated respondents have about their surgery. As expected, all of the continent respondents and 84 percent of the incontinent respondents believe that physicians can help people who have a urine loss condition and a large majority of all the 54 respondents also believe that physicians are effective in helping incontinent people.

The result of this community survey, documenting a 4.7 percent rate of surgical procedures to correct urine loss in women, appears to be contrary to the public perception that surgery is being overutilized as a treatment modality for female incontinence. In our initial report, 31 percent of all female respondents reported a stress type of urinary incontinence. ${ }^{\theta}$ If only 25 percent of the potential pool of respondents with stress incontinence are truly surgical candidates, then approximately 8 percent of all female respondents would be candidates for anti-incontinence surgery. The low rate of 
surgical intervention may be due to the fact that 59 percent of all survey respondents who are suffering from urinary incontinence have not told their physician about their condition. Even worse, only 27 percent of female respondents with stress type incontinence told their physician about their condition. ${ }^{6} \mathrm{~A}$ public education program may be useful in reaching these women.

Another major problem uncovered by our survey that may explain the low surgical prevalence was the fact that only 47 percent of incontinent respondents who told their physician about their incontinence received any treatment. ${ }^{6}$ It seems apparent that primary physicians need further education to update their knowledge on urinary incontinence to improve the management of these patients.

These survey results allow us to highlight several issues related to anti-incontinence surgery that need to be addressed in the future. There is a need to inform the public and the care providers of the many aspects of urinary incontinence. It also indicates the need to do further comprehensive research into the outcome of anti-incontinence surgery, not only the continence status, but other lower urinary tract symptoms that can negatively affect a successfully operated patient. It is our belief that a prospective long-term study involving an individual center or a multi-center study is needed to answer several questions raised by this survey.
1150 West Medical Center Drive Ann Arbor, Michigan 48109

(DR. DIOKNO)

\section{References}

1. Hadley HR, Zimmern PE, Staskin DR, and Raz S: Transvaginal needle bladder neck suspension, Clin Obstet Gynecol 12: 497 (1985).

2. McGuire EJ: Abdominal procedures for stress incontinence, Urol Clin North Am 12: 285 (1985).

3. Riggs JA: Retropubic cystourethropexy: a review of two operative procedures with long-term follow-up, Obstet Gynecol 68: 98 (1986).

4. Fleischer AN, Vinson RR, and Jumper B: Endoscopic vesicourethropexy for stress urinary incontinence. Experience at the medical center hospital in Vermont, Urology 24: 577 (1984).

5. Diaz DL, Fox BM, Walzak MP, and Nieh PT: Endoscopic vesicourethropexy. Experience and complications, Urology 24: 321 (1984).

6. Diokno AC, Brock BM, Brown MB, and Herzog AR: Prevalence of urinary incontinence and other urological symptoms in the noninstitutionalized elderly, J Urol 136: 1022 (1986).

7. Herzog AR, et al: Methods used to manage urinary incontinence by older adults in the community, J Am Geriatr Soc (in press).

8. Marshall VF, Vaughan ED Jr, and Parnell JP: Suprapubic veisocurethral suspension (Marshall, Marchetti-Kramtz) for stress incontinence, in Walsh PC, Gittes RF, Perlmutter AD, and Stamey TA (Eds): Campbells Urology, 5th Ed., Philadelphia, WB Saunders Co, 1986, chapt 73, p 2711.

9. Shortliffe LMD, and Stamey TA: Urinary incontinence in the female, $\mathrm{p} 2680$, op cit. $^{8}$

10. Spencer JR, O'Connor VJ Jr, and Schaeffer AJ: A comparison of endoscopic suspension of the vesical neck with suprapubic veisocurethropexy for treatment of stress urinary incontinence, $J$ Urol 137: 411 (1987).

11. Drukker BH: Anterior colporrhaphy, in Buchsbaum HJ and Schmidt JD (Eds): Gynecologic and Obstetric Urology, Philadelphia, WB Saunders Co, 1978, p 189.

12. Mundy AR: A trial comparing the Stamey bladder neck suspension procedure with colposuspension for the treatment of stress incontinence, Br J Urol 55: 687 (1983). 